\title{
Periodic Safety Update Reporting of Newly Launched Drugs through Hospitals - Need of the Hour: A Drug Controller General of India Initiative
}

\author{
Alkesh K Lokhande ${ }^{1}$, M M Prabhu ${ }^{2 *}$, M K Unnikrishnan ${ }^{1}$, Girish Thunga ${ }^{1}$ and M Surulivel Rajan ${ }^{1}$ \\ ${ }^{1}$ Department of Pharmacy Practice, Manipal College of Pharmaceutical Sciences, Manipal University, Manipal Karnataka, India \\ ${ }^{2}$ Department of Medicine, Kasturba Medical College and Hospital, Manipal University, Manipal Karnataka, India
}

\begin{abstract}
A Periodic Safety Update Report (PSUR) is comprise of most complete safety experience of drugsubmitted to the competent drug regulatory authorities at defined period of time. In India, PSURs for all newer drugs must be submitted every six month for first two years followed by annually for next two years to the Drug Controller General of India [DCG(I)], New Delhi. So far, it's been mandatory only to Marketing Authorization Holders (MAHs) to submit PSURs periodically to DCG(I), New Delhi. But, since 28 August 2012 DCG(I) has made it mandatory for hospitals in India to implement PSUR system for newly introduced drugs. In country like India where, lots of irregularity seen in safety surveillance of patients. We have very less active Adverse Drug Reaction (ADR) monitoring centers in function and a lot of determination is needed in order to collect drug safety data which may be carried out through active safety surveillance of therapeutic agents. Thus it has become important to comply with the requirement of DCG(I) and address the safety concern of our hospitalized patients. PSUR is the need of the hour to in our hospitals. We have to take steps for monitoring patients who are on newly introduced drugs and generate data for the reporting of PSURs to the DCG(I). This pioneering hospital based PSUR setup will create an environment for healthy safety reporting and helps the regulatory authorities for drug safety related decisions.
\end{abstract}

Keywords: Periodic safety update report; Drug Controller General of India; Adverse drug reaction

\section{Introduction}

Topic have been chosen to focus on the recent trend of drug safety reporting in India and latest amendment done by Indian Drug Regulatory Authority [DCG(I)] to explore the possibilities and betterment in drug safety surveillance. In country like India where, lots of irregularity observed in safety surveillance of patients. So far, it was only applicable to Marketing Authorization Holders (MAHs) to submit PSURs periodically to DCG(I), New Delhi. But, since 28 August 2012 it's been mandatory even for some leading hospitals in India.PSUR is the need of the hour to in our hospitals. While drug safety directly linked to patients that's why geneses of such drug safety surveillance system in each hospital is very much essential. This pioneering model hospital based PSUR setup will create an environment for healthy safety reporting and helps the regulatory authorities for drug safety related decisions. Such system will provide latest drug safety information, rationale for their use, risk-benefits, cost, outcome and effective use in clinical practice. It will promote understanding and clinical training to the entire health care practitioner working in hospital in the area of pharmacovigilance.

\section{Pharmacovigilance and Periodic Safety Update Reporting (PSUR)}

Pharmacovigilance is the science and activities relating to the detection, assessment, understanding and prevention of adverse effects or any other possible drug-related problems [1].

An adverse drug reaction is a response to a medicinal product which is noxious and unintended and which occurs at doses normally used in man for the prophylaxis, diagnosis or therapy of disease or for the restoration or modification of physiological function [2].

Pharmacovigilance made a long journey since its inception in the early 1960s followed by thalidomide disaster. Pharmacovigilance involves clinical activity with an association of population health
(Pharmacoepedemiology) and clinical research together [1].

Safety of drugs is underestimated in part, a study proved that approx. $57 \%$ of the community acquired adverse drug reactions are not predictable during hospital admission, which leads to improper management of the adverse event. Due to that, patient may further expose to additional hazards of drugs and resulting in increased hospitalization period [3].

We have very less active ADR monitoring centers in function and a lot of determination is needed in order to collect drug safety data which may be carried out through active safety surveillance of therapeutic agents [4]

Six-months intensive ADR reporting study carried out at medicine wards of tertiary care teaching hospital, revealed that, a total of 317 ADR were reported from 1438 patients admitted. Out of these, 195 and 6 ADRS were considered as moderate and severe respectively [5].

Despite awareness, practicing doctors do not report ADRs due to their busy schedule. Hence there is a need for alternative approach to identify, analyse and report the drug safety reports in order to minimise the incidence [6].

Indian pharmaceutical companies holding the marketing licence for a given drug are expected to maintain adequate provisions for

*Corresponding author: M Mukhyaprana Prabhu, Professor of Medicine Kasturba Medical College and Hospital, Manipal, Karnataka, India- 576104; Tel: +91-820-2922312/2922236; E-mail: mm.prabhu@manipal.edu

Received April 28, 2014; Accepted May 28, 2014; Published May 30, 2014

Citation: Lokhande AK, Prabhu MM, Unnikrishnan MK, Thunga G, Rajan MS (2014) Periodic Safety Update Reporting of Newly Launched Drugs through Hospitals-Need of the Hour: A Drug Controller General of India Initiative. Adv Pharmacoepidemiol Drug Saf 3: 155. doi:10.4172/2167-1052.1000155

Copyright: (c) 2014 Lokhande AK, et al. This is an open-access article distributed under the terms of the Creative Commons Attribution License, which permits unrestricted use, distribution, and reproduction in any medium, provided the original author and source are credited. 
pharmacovigilance systems to ensure the safety of their pharmaceutical products.

A Periodic Safety Updated Report (PSUR) is intended to provide an update of the worldwide safety experience of a medicinal product to competent drug regulatory authorities at defined time points postauthorisation. At these times, marketing authorisation holders (MAHs) are expected to provide succinct summary information together with a critical evaluation of the risk-benefit balance of the product in the light of new or changing information [7].

In India, it is the responsibility of pharmaceutical companies holding the marketing license should safeguard adequate pharmacovigilance obligation in the system to ensure the responsibility and liability of their marketed product.

Specifications of schedule Y of the Drug and Cosmetic act 1945 suggest the legislative requirement of pharmacovigilance in India. Reviewed and amended version of schedule $\mathrm{Y}$ dated $20^{\text {th }}$ January 2005 indicates the endless commitment of DCGI to ensure pharmaceutical companies are adequately complying with the pharmacovigilance obligations. The section under schedule $\mathrm{Y}$ entitled Post Marketing Surveillance (PMS) comprisesof all the details related to PSURs submission, PSUR Cycle, PSUR templates and their timeline and condition of reporting [8].

As mentioned under schedule $\mathrm{Y}$ for all new products, PSURs should be submitted for the initial 2 years every 6 months and after then annually for next two year, but in India none of the company is taking it seriously to report the PSURs in respective time frames. On $28^{\text {th }}$ August 2012 an order from DCG(I) office has been passed to all the MAHs of newer drugs that, they must adhere to the system and report the PSURs as indicated in Schedule Y. They have given additional 3 weeks period to submit previous PSURs reports [9].

DCGI move came just few weeks after the CDSCO office criticized for their oversight over mandatory safety reporting of newer drugs. It is mentioned in the reports submitted by parliamentary standing committee which is exclusively constituted to look after the matters related to deaths in clinical trials and their safety issues. In the document published in the May the committee reports that, when they asked DCG(I) office for PSUR data on 42 randomly selected drugs from its database. The DCG(I) office was only able to produce information for 8 drugs. This action referred a poor follow-up of regulatory authority over MAHs for patient safety surveillance. The committee recommends that manufacturer (MAHs) of newer drugs should be cautionedabout, unless they comply with mandatory rules on PSURs their products will face suspension of marketing approval [10].

\section{Need of PSUR}

In India around 294 Fixed Dose Combinations are in the market without conducting a local trial or without appropriate regulatory permissions. In 2007 CDSCO called on state drug controllers to withdraw them from market but the manufacturers stayed the order in the madras high court and the drugs were never withdrawn.Recently on $15^{\text {th }}$ Jan 2013 , CDSCO given 18 months period to test drugs not approved by India's CDSCO for their efficacy and safety to Indian drug manufacturers otherwise they will be pulled from market [11].

Although, a serious matter which is related directly to patients is getting delayed and manufacturers are playing with life of patients and we don't have stringent law in place to handle the situation.

Over the past few years, lots of drug were withdrawn worldwide based on the post marketing surveillance data. This underpins the need for such a surveillance system. PSURs submitted under post marketing surveillance of newly launched drugs have been whistleblowers towards the safety issues of drugs sold in the market. For instance, in September, 2004 after studies showed that Vioxx (rofecoxib) increases the risk of myocardial infarctions and strokes; Merck withdrew its anti-arthritis blockbuster drug. Due to safety concerns in the past few years, series of drugs been withdrawn from market including some of blockbuster drugs amongst them like lipid-lowering drug Lipobay (Baycol; cerivastatin), the anti-obesity drugs fenfluramine and dexfenfluramine, and several others. The latest data from the Indian drug regulatory authority CDSCO website indicates that around 90 drugs or their combinations were withdrawn from the market because of their low safety profile [12].

Newer law to recall the drugs from the market [13] and expansion of the reviewer panel for clinical trial and drug safety [14] is been taking place, they want more professionals to be clubbed with this so that we can resolve the situation and can make our health care system better.

Now, DCG(I) has made it mandatory for hospitals in India to implement PSUR for newly introduced drugs [15]. Thus it has become important to comply with the requirement of DCG(I) and address the safety concern of our hospitalised patients. Thus, PSUR is the need of the hour in all hospitals. We have to take steps for monitoring patients who are on newly introduced drugs and generate data for the periodic reporting of PSURs to the DCG(I).

\section{Basic Requirement to Establish PSUR System in Hospital}

To comply with the direction of DCG(I) to all the leading hospitals of India on mandatory drug safety reporting. They have to implement PSUR system in their hospital for regular submission of PSURs to the DCG(I), New Delhi. Before to initiate, take all the ethical permission from hospital ethical committee. There is a need to constitute one PSUR committee which will work exclusively for the PSUR system implementation and reporting. Include persons in the PSUR committee as much as possible from all the diverse areas of hospital. Which you presume will better help you to implement the system. (e.g. Medical Superintendent, Chief Pharmacist, Medical Operations Head and Nursing Head etc.)

After constituting a PSUR committee, now it's the responsibility of committee to finalize the list of all newer drugs for their safety reporting which are launched recently and are running in the hospital. One drug safety review panel should be constituted so that, PSUR station can avail the expert advice/comments over safety report/issues if required.

Before to initiate the drug safety reporting, reporters should be informed and trained on how it will be reported. Latest drug list, list of reported ADRs, standard ADR reporting form, Drug information leaflets should be prepared and circulated in all the wards of hospital. For manual reporting if convenient, keep one box at all nursing stations of hospital which will contain all these information leaflets and ADR reporting forms.

Below given chart illustrating the complete work flow of PSUR system from reporting of drug safety report to preparation of PSURs and their submission to DCG(I).

Steps to be followed as mentioned in flowchart for PSUR:

1. To provide necessary information and training to all health care professionals (Physicians, Nurses and Pharmacists etc.) 
Citation: Lokhande AK, Prabhu MM, Unnikrishnan MK, Thunga G, Rajan MS (2014) Periodic Safety Update Reporting of Newly Launched Drugs through Hospitals-Need of the Hour: A Drug Controller General of India Initiative. Adv Pharmacoepidemiol Drug Saf 3: 155. doi:10.4172/21671052.1000155

Page 3 of 4

on how to identify and report suspicious adverse drug reaction.

2. Preparation of drug information leaflets and circulation of drug information leaflets \& ADR reporting form for the newer drug recommended by DCGI at each nursing station of wards.

3. Identification and enrolment of the patients who are on the drugs recommended by DCGI to follow. Either by accessing online drug dispensing database available at chief pharmacist office or manual checks in the files of patients.

4. Verbal/telephonic instructions to the respective department where these drugs are dispensed to keep these patient under observation and if any suspected ADR found, reporting of it in to an ADR reporting form as mentioned or instructed.

5. Reporting of ADRs through healthcare professionals on particular drugs by using any suitable method.

6. To take expert advice from safety review panel if any serious safety issues associated with the ADR.

7. Collection of the data from each ward, nursing, pharmacy stations and feeding of the relevant ADR data in to Case Record Form (CRF).

8. Review and analysis of the reported ADRs in each month's interval.

9. Reporting of this processed Adverse Events (AEs) as a PSUR periodically to the DCGI, New Delhi, India.

Schematic Presentation of Process and Work Flow (ADR reporting, PSUR preparation and submission)
It is advisable to have some basic softwares and tools to use during processing of ADRs like: MedDRA (to assign term to unidentified ADR), Hartwig scale [16] (ADR severity assessment), Thompson and Rawlins scale [17,18] (for classification of types of ADRs), Naranjo algorithm [19] (to assess causality), ADR frequency scale [20] and Schumock and Thornton scale [21] (to check preventability of ADRs) etc. It will be better if risk/benefit analysis $[22,23]$ and cost analysis will be added to interpret and conclude result in better way.

\section{Conclusion}

Some regulators believe that, firstly all new drugs should confirm its acceptable risk-benefit profile and during that period only grant them probationary license [11]. While drug safety directly linked to patients that's why geneses of such drug safety surveillance system in each hospital is very much essential. Study of its kind from the hospitals side, which will generate accurate drug safety surveillance data for the newly recommended drugs. It will contribute to DCG(I), to take decision on issues related to safety of newer drugs and to validate the accuracy of drug safety data (PSURs) submitted from the MAHs side. The PSUR data submitted by MAHs is inaccessible and confidential, because they don't want to disclose the result which may lose their products market stake. This study will provide most accurate result related to products and will become available to access to health care professional and public in the form of PSUR newsletter and/or publication of results in to the journals. Study will provide latest drug safety information, rationale for their use, risk-benefits, cost, outcome and effective use in clinical practice. Such Studies will promote understanding and clinical training to the entire health care practitioner in the area of

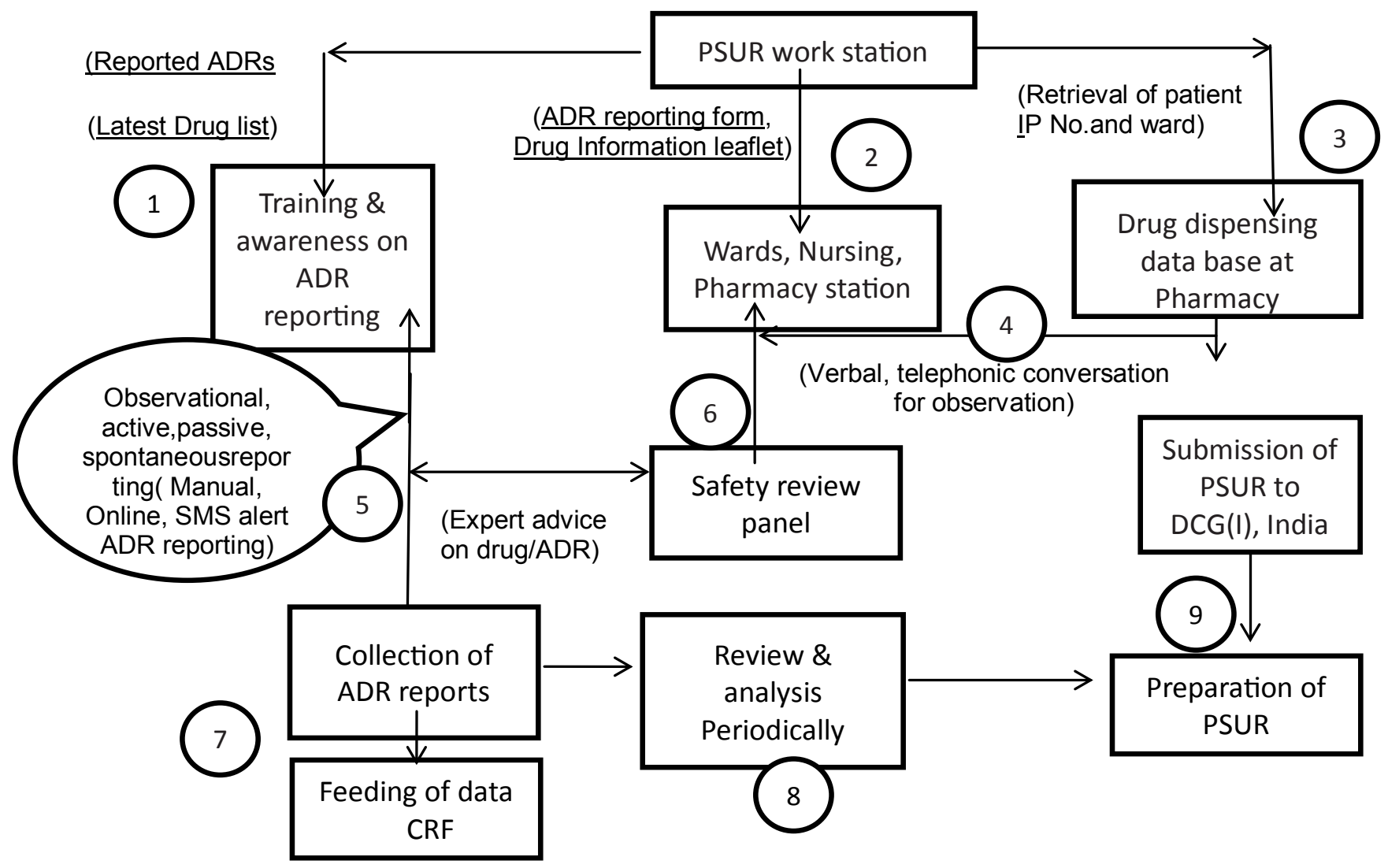


Citation: Lokhande AK, Prabhu MM, Unnikrishnan MK, Thunga G, Rajan MS (2014) Periodic Safety Update Reporting of Newly Launched Drugs through Hospitals-Need of the Hour: A Drug Controller General of India Initiative. Adv Pharmacoepidemiol Drug Saf 3: 155. doi:10.4172/21671052.1000155

Page 4 of 4

pharmacovigilance.

\section{References}

1. Richesson RL, Andrews JE (2012) Clinical Research Informatics, Health Informatics, Springer-Verlag London Limited: 367-386.

2. Edwards IR, Aronson JK (2000) Adverse drug reactions: definitions, diagnosis, and management. Lancet 356: 1255-1259.

3. Dormann H, Criegee-Rieck M, Neubert A, Egger T, Geise A, et al. (2003) Lack of awareness of community-acquired adverse drug reactions upon hospital admission : dimensions and consequences of a dilemma. Drug Saf 26: 353362

4. Sharma H, Aqil M, Imam F, Alam S, Kapur P, et al. (2007) A pharmacovigilance study in the department of medicine of a university teaching hospital. Pharmacy Practice 5: 46-49.

5. Thiagu R (2010) Modeling of predictors for adverse drug reactions and Pharmacoeconomic Impact in atertiary care hospital [PhD thesis] Manipal: Manipal University; 2010 [cited 2012 Dec. 12 available from manipal university digital repository.

6. Majagi SI, Patil PA (2011) Pharmacovigilance: Recent Research in Science and Technology 3: 33-34

7. Periodic Safety Update Reports

8. Arora D (2008) Pharmacovigilance obligations of the pharmaceutical companies in India. Indian J Pharmacol 40: S13-16.

9. http://www.cdsco.nic.in/writereaddata/Submission\%20of\%20PSUR.pdf

10. India. Parliament. Rajyasabha. Department-Related Parliamentary Standing committee on Health and Family Welfare. Fifty-ninth report on the functioning of the central drugs standard control organisation (cdsco). 8th May 2012.

11. http://www.in-pharmatechnologist.com/Regulatory-Safety/CDSCO-Sets-18Month-Deadline-for-Efficacy-Safety-Testing

12. http://cdsco.nic.in/writereaddata/drugs $\% 20$ banned $\% 20$ in $\% 20$ thed\%20country. pdf

13. www.cdsco.nic.in/writereaddata/Guidlines $\% 20$ on $\% 20$ Recall.pdf?

14. www.cdsco.nic.in/writereaddata/Expansion\%20of\%20Panel.pdf?

15. Reporting of Periodic Safety Update Reports (PSURs); letter from DCGI India to Kasturba Hospital, Manipal. In 28 august 2012

16. Naranjo CA, Busto U, Sellers EM, Sandor P, Ruiz I, et al. (1981) A method for estimating the probability of adverse drug reactions. Clin Pharmacol Ther 30 239-245.

17. Dollery CT, Rawlins MD (1977) Monitoring adverse reactions to drugs. Br Med J 1: 96-97.

18. http://www.mhra.gov.uk/ConferencesLearningCentre/LearningCentre/ Medicineslearningmodules/Pharmacovigilancelearningmodule/ pharmacovigilancelearningmodule/index.htm

19. National Pharmacovigilance Protocol, Ministry of Health and Family Welfare (India): 2003.

20. Srinivasan R, RamyaG (2011) adverse drug reaction-causality assessment, intnl. J res In pharm Chem 1: 606-612.

21. McDonnell PJ, Jacobs MR (2002) Hospital admissions resulting from preventable adverse drug reactions. Ann Pharmacother 36: 1331-1336.

22. Arlett PR (2001) Risk benefit assessment. Pharmaceutical Physician 12: 12-17.

23. Ernst E, Resch KL (1996) Risk-benefit ratio or risk-benefit nonsense? J Clin Epidemiol 49: 1203-1204. 